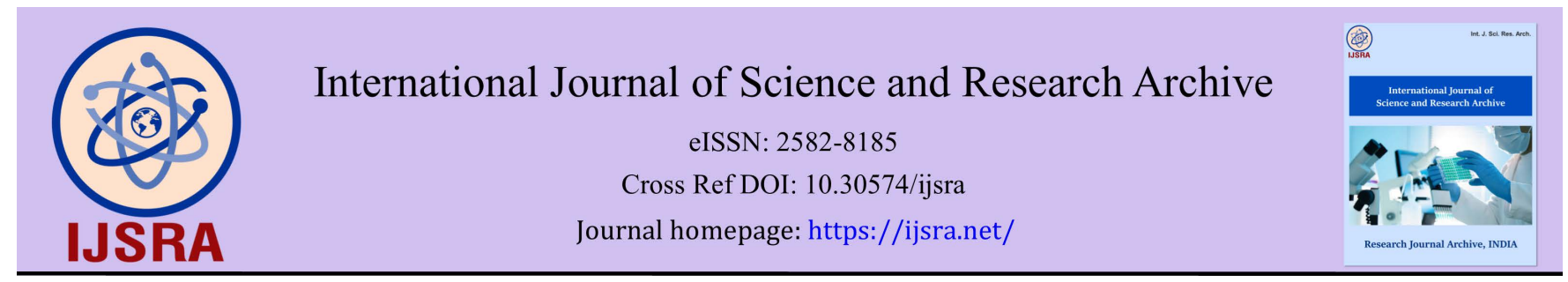

(RESEARCh ARTiCle)

\title{
Community knowledge towards electric vehicles and policy part II: A pilot study of Edmonton Height underserved neighborhood in Huntsville, Alabama
}

\author{
Jacob Oluwoye * \\ College of Agricultural, Life and Natural Sciences, Department of Community and Regional Planning, Alabama A\&M \\ University, Huntsville, Alabama, USA.
}

International Journal of Science and Research Archive, 2021, 02(02), 126-132

Publication history: Received on 26 March April 2021; revised on 03 May 2021; accepted on 06 May 2021

Article DOI: https://doi.org/10.30574/ijsra.2021.2.2.0067

\begin{abstract}
Introduction: Electric Vehicles (EV) are fast emerging globally as a viable alternative to traditional fossil fuel burning cars and are now being presented as a resolution for the problem of dependence of fossil fuels, increasing emissions, and other environmental issues.

Purpose and Objective: The study explores the neighborhood knowledge toward green mobility and the objective of this paper is to investigate and examine neighborhood perceptions and understand their knowledge towards the electric vehicle. The research paper goal necessitated the knowledge of the underserved community towards green mobility.
\end{abstract}

Methods: Following the literature review research phase, the researcher conducted several semi structured interviews with underserved community. To best augment the quantitative, data were gathered from underserved Edmonton Height community, through the design of questionnaire survey. Data collection took place during the last two weeks of October 2018. Neighborhood households were approached during the day and evening in their residents using a structured questionnaire.

Results: The analysis reveals that that $60 \%$ of the respondents not aware of plug-in EV incentives (such as tax credit, rebate, high occupancy lane access, reduced tolls, lower vehicle registration rates, or discounted electricity rates) offered by the federal government; their state government; local community; their electricity provider; their employer, while $10 \%$ indicated federal government and 10\% local community and 5\% indicated electric providers, 5\% employers and $5 \%$ state government. However, the pilot results are a useful estimate of the number of households residents residing in Edmonton Heights don't know that plug-in EVs can be recharged from a regular home outlet.

Conclusion: The paper concludes that the progress that the electric vehicle industry has seen in recent years is not only extremely welcomed, but highly necessary considering the increasing global greenhouse gas levels and it should be noted that a range of technology options is being aggressively explored to facilitate the transition to a more sustainable transport system. Near term, technologies such as EVs can provide sustainable mobility and help alleviate some of the problems created by conventional vehicle powered by fossil fuels. Notwithstanding, the pilot results are a useful estimate of the number of households residents residing in Edmonton Heights don't know that plug-in EVs can be recharged from a regular home outlet.

Keywords: Community knowledge; Electric Vehicles; Electric Vehicle Policy; Underserved Neighborhood

\footnotetext{
* Corresponding author: Jacob Oluwoye

College of Agricultural,Life and Natural Sciences,Department of Community and Regional Planning, Alabama A\&M University, Huntsville, Alabama, USA.

Copyright (@ 2021 Author(s) retain the copyright of this article. This article is published under the terms of the Creative Commons Attribution Liscense 4.0.
} 


\section{Introduction}

While the transportation sector has benefited immensely from the event and use of combustion engines (ICE) in 1807, there's a growing awareness of the negative impact fossil fuels have brought upon the well-being of the environment and society. ICE powered vehicles are now the most global source of $\mathrm{CO}_{2}$ emissions [1]. As a result, Electric Vehicles 1 (EV) are fast emerging as a viable alternative to traditional fuel burning cars.

A combination of high fuel costs, concerns about petroleum availability, and environmental issues associated with conventional vehicles powered by fossil fuels are driving interests in electric vehicles (EVs). Large-scale deployment of EVs can play a significant role in addressing some of these problems. Despite the benefits of EVs, several obstacles need to be overcome before EVs will be widely adopted. This research focuses on two socio-technical issues that affect widespread adoption and sustainability of EVs, consumer attitudes and perceptions, and supply chain risks of raw materials for EV battery technology.

A combination of high fuel costs, concerns about petroleum availability, and environmental issues related to conventional vehicles powered by fossil fuels are driving interests in electric vehicles (EVs). Large-scale deployment of EVs can play a big role in addressing a number of these problems. Despite the advantages of EVs, several obstacles got to be overcome before EVs are going to be widely adopted. This research focuses on two socio-technical issues that affect widespread adoption and sustainability of EVs, consumer attitudes and perceptions, and provide chain risks of raw materials for EV battery technology.

[2] reported that various reports indicate that the sales of electric vehicles will continue to grow, and the feasibility is of supplying the growing several electric vehicles with fuel remains a significant issue. Notwithstanding, public charging stations are massively outnumbered by gas stations as reported by [2]. Therefore, many electric vehicle owners find that it is more convenient to charges their vehicles at a home and can get complicated in a community association where residents share parking areas and the costs of supplying their association with an electricity.

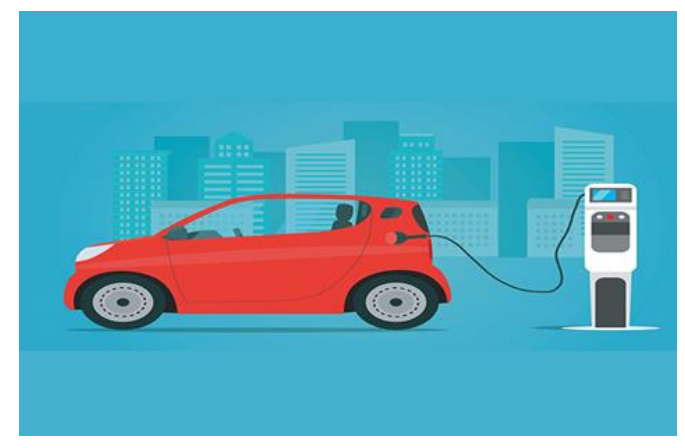

Figure 1 Example of EV Charging Station

\section{State of the art}

\subsection{Technological-Driving range}

Previous studies have discussed and identified EV barriers in reference to technological, economic, social, political, and environmental factors in a world context [3]; [4]; [5]; [1]. A 2010 Deloitte survey [4] of 2,000 US vehicle purchasers showed that $22 \%$ of respondents stated limited golf range together of the main reasons in deferring purchasing an EV. Similar findings are presented in surveys wiped out 17 countries [5] and a survey done by Oxford Brookes University [3]. The perfect golf range expected by consumers has been found to be between $300 \mathrm{~km}$ to $450 \mathrm{~km} \mathrm{[4],} \mathrm{[5];} \mathrm{[3];} \mathrm{[1].}$ However, arguably this problem may be a perceived instead of a true issue, with 85\% of the 2010 Deloitte survey respondents travelling but $160 \mathrm{~km}$ per day. Similar disparities between ranges expectations vs. actual performance required were found by a UK National Travel survey [3] which identifies that EVs with a 150km golf range could easily satisfy over $90 \%$ of car drivers' daily use.

The discussions below were extracted from [6] paper entitled "Community Attitude towards Electric Vehicle: A Pilot Study of Edmonton Heights Underserved Neighborhood in Huntsville, Alabama" published in East African Scholars Publisher, Kenya Volume-3 | Issue-6 |June-2020|. Electric vehicles (EVs) are now being presented as a resolution for the matter of dependence of fossil fuels, increasing emissions, and other environmental issues. Road transport adds to just 
about one-fifth of the ecu Commissions' total emissions of $\mathrm{CO} 2$, the most greenhouse emission [8]. Furthermore, $\mathrm{CO} 2$ emissions from road transport increased by $23 \%$ between 1990 and 2010 and are still rising within the EU. Also, transportation contributes to 35\% of greenhouse emission house emissions taking up the electrical sector in 2016. Stating the importance of tackling global climate change, many governments have created policies for reducing $\mathrm{CO} 2$ emissions by encouraging the development, introduction, and implementation of EVs [8] In spite of the purported positive environmental consequences of electrifying the light-duty vehicle fleet the share of EVs within the total number of vehicles sold remains small. In 2011, the EV market share was only $0.06 \%$ of the 51.1 million light-duty vehicles sold within the EU, U.S., and therefore the key Asian markets (European Commission, 2012). One perception of such modest adoption figures is that the mass acceptance of EVs is especially reliant on consumers' perception of them [9]. Therefore, so as to market EV adoption, it's important to know how buyers perceive EVs and what the possible drivers for and barriers against consumer EV adoption are.

In the consumer EV adoption research, environmental beliefs and consumer awareness of environmental issues and individual's effects are alleged to affect the aims to get EVs [10]; [11]; [12]; [13]. It's been debated that consumer concern for the environment won't necessarily end in pro-environmental behavior and there's a niche between the environmental attitude and behavior [14]; [15]; [16]. Symbolic meanings of products and their relationship with selfidentity and purchases of products are described supported distinctive psychological and sociological theories within the consumer EV adoption literature. [17] model of sign, [18] self-image congruency theory, [19] narratives of self and [20] costly signaling theory are the theoretical basis within the literature which account for EV symbolism and consumer adoption. [17] states that a product sort of a car may be a signifier or symbol of ideas and meanings. An example of signified meaning within the case of EVs may be a concern for the environment.

In another study, [21] show that consumers' expectations of complexity from technological innovation may be a significant think about creating emotions, which consequently affect innovation evaluations and thus the acquisition decision. The studies by [9] and [22] contemplate pro-environmental orientation as a self-identity or way. The second self-identity, car-authority identity [9] are often thought of as a subclass of technology orientation [22] where individuals are experts on cars. However, car-authority consumers state neither positive nor negative perceptions of EV attributes and weren't convinced about the environmental impacts of EVs [9] while non-greens with technologyoriented ways are doubtless to adopt EVs [22] For potential buyers of EVs, the perception of positive feelings from driving an EV was positively correlated with consumer attitudes and intentions to adopt EVs [23]. However, this study doesn't provide further information on the sort of positive feelings that buyers anticipated to experience with EVs.

\section{Purpose of the paper}

The study explores the community attitudes and knowledge toward the green mobility and the purpose of this paper is to investigate and examine neighborhood perceptions and understand their knowledge towards electric vehicle.

\section{Methods}

The research paper goal necessitated the attitudes and knowledge of the underserved community towards green mobility. Following the literature review research phase, the researcher conducted a number of semi structured interviews with underserved community. To best augment the quantitative, data were gathered from underserved Edmonton Height community, through the design of questionnaire survey. Data collection took place during the last two weeks of October 2018. Neighborhood households were approached during the day and evening in their residents using a structured questionnaire. Overall, 30 people were approached, 20 of which were qualified for sample inclusion in the time frame of the survey ( 66.7 percent).

\section{Presentation of Data and Results}

This research paper primarily adopts a positivist paradigm with the focus on quantitative, empirical data collection and analysis [24]. 
Table 1 Descriptive Statistics

\begin{tabular}{|l|l|l|l|l|l|}
\hline & $\mathbf{N}$ & Minimum & Maximum & Mean & Std. Deviation \\
\hline VAR00020PRO & 20 & 1.00 & 3.00 & 1.9500 & 0.94451 \\
\hline VAR00021POCO & 20 & 1.00 & 3.00 & 2.3500 & 0.87509 \\
\hline VAR00022PRH & 20 & 1.00 & 3.00 & 2.3500 & 0.93330 \\
\hline VAR00023PRCE & 20 & 1.00 & 3.00 & 1.7500 & 0.96655 \\
\hline VAR00024MAO & 20 & 1.00 & 3.00 & 2.3000 & 0.92338 \\
\hline VAR00025DCS & 20 & 1.00 & 3.00 & 1.8500 & 0.81273 \\
\hline VAR00026API & 19 & 1.00 & 6.00 & 4.7895 & 1.84327 \\
\hline VAR00027BVWT & 20 & 2.00 & 2.00 & 2.0000 & 0.00000 \\
\hline Valid N (list wise) & 19 & & & & \\
\hline
\end{tabular}

VAR00020PRO =Plug-in electric vehicles reduce oil use;

VAR00021POCO=Plug-in electric vehicles are cheaper to operate than gasoline vehicles;

VAR00022PRH=Plug-in electric vehicles can be recharged from a regular home outlet;

VAR00021PRCE=Plug-in electric vehicles reduce climate emissions compared to an average gasoline powered vehicle; VAR00024MAO=Many major automakers should offer at least one plug-in vehicle for sale;

VAR00025DCS=Difficult to find credible sources of information about plug-in vehicles;

VAR00026API=Awareness of plug-in electric vehicle incentives;

VAR00027BVWT=Buying a vehicle without a test-drive.

Table 2 below reveals that $45 \%$ underserved community agreed that the "plugin electric vehicles reduced oil use" while $15 \%$ disagreed and $40 \%$ do not know that plug-in EV will reduce oil use.

Table 2 Plug-in electric vehicles reduce oil use

\begin{tabular}{|l|l|l|l|l|l|}
\hline \multicolumn{2}{|c|}{} & Frequency & Percent & $\begin{array}{l}\text { Valid } \\
\text { Percent }\end{array}$ & $\begin{array}{l}\text { Cumulative } \\
\text { Percent }\end{array}$ \\
\hline \multirow{4}{*}{ Valid } & 1.00 & 9 & 45.0 & 45.0 & 45.0 \\
\cline { 2 - 6 } & 2.00 & 3 & 15.0 & 15.0 & 60.0 \\
\cline { 2 - 6 } & 3.00 & 8 & 40.0 & 40.0 & 100.0 \\
\cline { 2 - 6 } & Total & 20 & 100.0 & 100.0 & \\
\hline
\end{tabular}

1.00 Agree, 2.00 Disagree, 3.00 Don't Know.

Furthermore, as noted in table 3 that the knowledge of underserved community in relation to "plug-in EVs are often cheaper to operate than cheaper gasoline vehicles" while $25 \%$ agreed and $15 \%$ disagreed.

Table 3 Plug-in electric vehicles are cheaper to operate than gasoline vehicles

\begin{tabular}{|c|c|c|c|c|c|}
\hline \multicolumn{2}{|c|}{} & Frequency & Percent & Valid Percent & Cumulative Percent \\
\hline \multirow{3}{*}{ Valid } & 1.00 & 5 & 25.0 & 25.0 & 25.0 \\
\cline { 2 - 6 } & 2.00 & 3 & 15.0 & 15.0 & 40.0 \\
\cline { 2 - 6 } & 3.00 & 12 & 60.0 & 60.0 & 100.0 \\
\cline { 2 - 6 } & Total & 20 & 100.0 & 100.0 & \\
\hline
\end{tabular}

As one can see from table 4 that $65 \%$ of the sample of residents residing in Edmonton Heights don't know that plug-in EVs can be recharged from a regular home outlet", while $30 \%$ agreed and $5 \%$ disagreed. Notwithstanding, table 5 shows 
that $60 \%$ responded that "plug-in EVs reduce climate emissions compared to an average gasoline-powered vehicle", $35 \%$ do not know and $5 \%$ disagreed with statement.

Table 4 Plug-in electric vehicles can be recharged from a regular home outlet

\begin{tabular}{|c|c|c|c|c|c|}
\hline \multicolumn{2}{|c|}{} & Frequency & Percent & Valid Percent & Cumulative Percent \\
\hline \multirow{3}{*}{ Valid } & 1.00 & 6 & 30.0 & 30.0 & 30.0 \\
\cline { 2 - 6 } & 2.00 & 1 & 5.0 & 5.0 & 35.0 \\
\cline { 2 - 6 } & 3.00 & 13 & 65.0 & 65.0 & 100.0 \\
\cline { 2 - 6 } & Total & 20 & 100.0 & 100.0 & \\
\hline \multicolumn{6}{|c}{1.00 Agree, 2.00 Disagree, 3.00 Don't Know. }
\end{tabular}

Table 5 Plug-in electric vehicles reduce climate emissions compared to an average gasoline powered vehicle

\begin{tabular}{|c|c|c|c|c|c|}
\hline \multicolumn{2}{|c|}{} & Frequency & Percent & Valid Percent & Cumulative Percent \\
\hline \multirow{3}{*}{ Valid } & 1.00 & 12 & 60.0 & 60.0 & 60.0 \\
\cline { 2 - 6 } & 2.00 & 1 & 5.0 & 5.0 & 65.0 \\
\cline { 2 - 6 } & 3.00 & 7 & 35.0 & 35.0 & 100.0 \\
\cline { 2 - 6 } & Total & 20 & 100.0 & 100.0 & \\
\hline \multicolumn{7}{|c}{1.00 Agree, 2.00 Disagree, 3.00 Don't Know } \\
\end{tabular}

It should be noted here that $60 \%$ of the respondents don't know that "many major automakers (e.g., Ford, GM, Nissan) offer at least on plug-in EV module for sale", 30\% agreed while 10\% disagreed as reveals in table 6. Furthermore, table 7 reveals that $40 \%$ of the respondents agreed with the statement that "it is difficult to find credible sources of information about plug-in electric vehicles" while 35\% disagreed and 25\% don't know.

Table 6 Many major automakers should offer at least one plug-in vehicle model for sale

\begin{tabular}{|l|l|l|l|l|l|}
\hline \multicolumn{2}{|c|}{} & Frequency & Percent & Valid Percent & Cumulative Percent \\
\hline \multirow{3}{*}{ Valid } & 1.00 & 6 & 30.0 & 30.0 & 30.0 \\
\cline { 2 - 6 } & 2.00 & 2 & 10.0 & 10.0 & 40.0 \\
\cline { 2 - 6 } & 3.00 & 12 & 60.0 & 60.0 & 100.0 \\
\cline { 2 - 6 } & Total & 20 & 100.0 & 100.0 & \\
\hline \multicolumn{5}{|c|}{1.00 Agree; 2.00 Disagree; 3.00 Don't Know. } \\
\hline
\end{tabular}

Table 7 Difficult to find credible sources of information about plug-in vehicles

\begin{tabular}{|l|l|l|l|l|l|}
\hline \multicolumn{2}{|c|}{} & Frequency & Percent & Valid Percent & Cumulative Percent \\
\hline \multirow{3}{*}{ Valid } & 1.00 & 8 & 40.0 & 40.0 & 40.0 \\
\cline { 2 - 6 } & 2.00 & 7 & 35.0 & 35.0 & 75.0 \\
\cline { 2 - 6 } & 3.00 & 5 & 25.0 & 25.0 & 100.0 \\
\cline { 2 - 6 } & Total & 20 & 100.0 & 100.0 & \\
\hline
\end{tabular}

In table 8, one can see that $60 \%$ of the respondents indicated none to the statement that they are aware of plug-in EV incentives (such as tax credit, rebate, high occupancy lane access, reduced tolls, lower vehicle registration rates, or discounted electricity rates) offered by the federal government; their state government; local community; their electricity provider; their employer, while $10 \%$ indicated federal government and $10 \%$ local community and $5 \%$ indicated electric providers, $5 \%$ employers and $5 \%$ state government. 
Table 8 Awareness of plug-in electric vehicle incentives

\begin{tabular}{|c|c|c|c|c|c|}
\hline & & Frequency & Percent & Valid Percent & Cumulative Percent \\
\hline Valid & 1.00 & 2 & 10.0 & 10.5 & 10.5 \\
\hline & 2.00 & 1 & 5.0 & 5.3 & 15.8 \\
\hline & 3.00 & 2 & 10.0 & 10.5 & 26.3 \\
\hline & 4.00 & 1 & 5.0 & 5.3 & 31.6 \\
\hline & 5.00 & 1 & 5.0 & 5.3 & 36.8 \\
\hline & 6.00 & 12 & 60.0 & 63.2 & 100.0 \\
\hline & Total & 19 & 95.0 & 100.0 & \\
\hline Missing & System & 1 & 5.0 & & \\
\hline Total & & 20 & 100.0 & & \\
\hline
\end{tabular}

\section{Conclusion}

The paper concludes that the progress that the electric vehicle industry has seen in recent years is not only extremely welcomed, but highly necessary in light of the increasing global greenhouse gas levels and it should be noted that a range of technology options is being aggressively explored to facilitate the transition to a more sustainable transport system. Near term, technologies such as EVs can provide sustainable mobility and help alleviate some of the problems created by conventional vehicle powered by fossil fuels. These vehicle technologies are beginning to penetrate the market; however, this analysis shows that there are still some significant hurdles facing EVs before they can be available in the mainstream market.

The analysis examined community neighborhood of Edmonton, Alabama perceptions and knowledge toward EVs and EV policy, in order to better understand perceived barriers to EV residents of underserved community and identify what sort of public policies would underserved neighborhood of Edmonton find most likely to help them choose an EV for their next vehicle. The analysis reveals that that $60 \%$ of the respondents not aware of plug-in EV incentives (such as tax credit, rebate, high occupancy lane access, reduced tolls, lower vehicle registration rates, or discounted electricity rates) offered by the federal government; their state government; local community; their electricity provider; their employer, while $10 \%$ indicated federal government and $10 \%$ local community and $5 \%$ indicated electric providers, 5\% employers and $5 \%$ state government. However, the pilot results are a useful estimate of the number of households residents residing in Edmonton Heights don't know that plug-in EVs can be recharged from a regular home outlet.

\section{Compliance with ethical standards}

\section{Acknowledgments}

I am particularly grateful to my postgraduate transportation planning students who volunteers for the pilot data collection used in this paper.

\section{Statement of informed consent}

Informed consent was obtained from all individual participants included in the study.

\section{References}

[1] Lemon S, Miller A. 'Electric vehicles in New Zealand: from passenger to driver? A National Energy Research Institute invited white paper'. National Energy Research Institute (NERI), University of Canterbury: Christchurch, New Zealand. 2013.

[2] Savitt D. Electric car charging stations in community associations: Five things to consider. Posted in Switch to the Business and Financial Law Blog. 25 February 2020. 
[3] Element Energy Limited. Pathways to high penetration of electric vehicles. Final report for the Committee on Climate Change Element Energy Ltd.: Cambridge, UK. December 2013.

[4] Giffi C, Gardner M, Hill R, Hasegawa M. Gaining traction: A customer view of electric vehicle mass adoption in the U.S. automotive market. (pp. 1-20). Deloitte Development LLC. 2010.

[5] Giff C, Vitale Jr J, Drew M, Kuboshima Y, Sase M. Unplugged: Electric vehicle realities versus consumer expectations (pp 1-32). Deloitte Global Services Ltd. 2011.

[6] Oluwoye J. Community Attitude towards Electric Vehicle: A Pilot Study of Edmonton Heights Underserved Neighborhood in Huntsville, Alabama" published in East African Scholars Publisher, Kenya Volume-3 Issue-6 June-2020.

[7] European Commission. Transport. Clean Transport. 2012.

[8] Brady J, O’Mahony M. Travel to work in Dublin. The potential impacts of electric vehicles on climate change and urban air quality. Transp. Res. DTransp. Environ. 2011; 16(2): 188-193.

[9] Schuitema G, Anable J, Skippon S, Kinnear N. The role of instrumental, hedonic and symbolic attributes in the intention to adopt electric vehicles. Transp. Res. A Policy Pract. 2013; 48: 39-49.

[10] Lane B, Potter S. The adoption of cleaner vehicles in the UK: exploring the consumer attitude-action gap. J. Cleaner Prod. 2007; 15(11-12): 1085-1092.

[11] Carley S, Krause RM, Lane BW, Graham JD. Intent to purchase a plug-in electric vehicle: a survey of early impressions in large US cites. Transp.Res. D Transp. Environ. 2013; 18: 39-45.

[12] Egbue 0, Long S. Barriers to widespread adoption of electric vehicles: An analysis of consumer attitudes and perceptions. Energy Policy. 2012; 48: 717-729.

[13] Skippon S, Garwood M. Responses to battery electric vehicles: UK consumer attitudes and attributions of symbolic meaning following directexperience to reduce psychological distance. Transp. Res. D Transp. Environ. 16 (7), 525-531.

[14] Oliver JD, Rosen DE. Applying the environmental propensity framework: a segmented approach to hybrid electric vehicle marketing strategies. J.Mark. Theory Pract. 2010; 18(4): 377-393.

[15] Kollmuss A, Agyeman J. Mind the gap: why do people act environmentally and what are the barriers to proenvironmental behavior? Environ. Educ.Res. 2002; 8(3).

[16] Stern PC. Toward a coherent theory of environmentally significant behavior. 2000; 56(3): 407-424.

[17] Saussure F. Course in General Linguistics. McGraw Hill, New York. 1965.

[18] Sirgy JM. Self-Congruity. Praeger, New York, USA. 1986.

[19] Giddens A. Modernity and Self-Identity. Stanford University Press, Stanford. 1991.

[20] Miller GF. Spent: Sex, Evolution, and Consumer Behavior. Viking, New York, NY. 2009.

[21] Wood SL, Moreau CP. From fear to loathing? how emotion influences the evaluation and early use of innovations. J. Marketing. 2006; 70: 44-57

[22] Axsen J, TyreeHageman J, Lentz A. Lifestyle practices and pro-environmental technology. Ecol. Econ. 2012; 82: 64-74.

[23] Moons I, De Pelsmacker P. Emotions as determinants of electric car usage intention. Journal of Marketing Management. 2012; 28(3-4): 195-237.

[24] Creswell, J. Research Design: Qualitative, Quantitative, and Mixed Methods Approaches. 4th edition. Sage publications: Thousand Oaks, California, USA. 2014. 